\title{
Hypoxic-Ischemic Injury Stimulates Subventricular Zone Proliferation and Neurogenesis in the Neonatal Rat
}

\author{
JENNIFER ONG, JENNIFER M. PLANE, JACK M. PARENT, AND FAYE S. SILVERSTEIN \\ Departments of Pediatrics [J.O., J.M. Plane, F.S.S.] and Neurology [J.M. Plane, J.M. Parent, F.S.S.], \\ University of Michigan, Ann Arbor, MI 48109
}

\begin{tabular}{|c|c|}
\hline \multicolumn{2}{|c|}{ ABSTRACT } \\
\hline $\begin{array}{l}\text { Neurogenesis persists throughout life in the rodent subven- } \\
\text { tricular zone (SVZ) and increases in the adult after brain injury. } \\
\text { In this study, postnatal day } 7 \text { (P7) rats underwent right carotid } \\
\text { artery ligation followed by } 8 \% \mathrm{O}_{2} \text { exposure for } 90 \text { min, a } \\
\text { lesioning protocol that resulted in ipsilateral forebrain hypoxic- } \\
\text { ischemic (HI) injury. The effects of } \mathrm{HI} \text { injury on SVZ cell } \\
\text { proliferation and neurogenesis were examined } 1-3 \text { wk later by } \\
\text { morphometric measurement of dorsolateral SVZ size; by immu- } \\
\text { noassays to detect incorporation of bromodeoxyuridine (BrdU) } \\
\text { in proliferating cells; and by immunoassays of doublecortin, a } \\
\text { microtubule-associated protein expressed only by immature neu- } \\
\text { rons. For determining the cell phenotypes of newly generated } \\
\text { cells, tissue sections were double labeled with antibodies to BrdU } \\
\text { and markers of mature neurons (neuronal nuclear protein), as- } \\
\text { trocytes (glial fibrillary acidic protein), or oligodendroglia (RIP). } \\
\text { HI injury resulted in enlargement of the ipsilateral SVZ at } \\
\text { P14-28 and a corresponding increase in BrdU cell numbers both } \\
\text { in the ipsilateral SVZ and striatum at P21. HI injury also } \\
\text { stimulated SVZ neurogenesis, based on increased doublecortin }\end{array}$ & $\begin{array}{l}\text { immunostaining in the SVZ ipsilateral to lesioning at P14-28. } \\
\text { However, } 4 \text { wk after HI injury, in the lesioned striatum, although } \\
\text { BrdU/glial fibrillary acidic protein and BrdU/RIP-labeled cells } \\
\text { were identified, no BrdU/neuronal nuclear protein double-labeled } \\
\text { cells were found. These results suggest that although acute } \\
\text { neonatal HI injury stimulates SVZ proliferation and neurogen- } \\
\text { esis, there is inadequate trophic support for survival of newly } \\
\text { generated neurons. Identification of the trophic factors that en- } \\
\text { hance maturation and survival of immature neurons could pro- } \\
\text { vide important clues for improving recovery after neonatal brain } \\
\text { injury. (Pediatr Res 58: 600-606, 2005) } \\
\text { BrdU, bromodeoxyuridine } \\
\text { GFAP, glial fibrillary acidic protein } \\
\text { HI, hypoxic-ischemic } \\
\text { NeuN, neuronal nuclear protein } \\
\text { P, postnatal day } \\
\text { SVZ, subventricular zone }\end{array}$ \\
\hline
\end{tabular}

The striatal subventricular zone (SVZ) adjacent to the lateral ventricle is a forebrain region in which neurogenesis persists postnatally. The SVZ contains a population of stem cells and more mature progenitors of neurons, astrocytes, and oligodendrocytes $(1,2)$. These cells do not express the proteins that distinguish mature neurons or glia. Normally, neural progenitors from the SVZ migrate along the rostral migratory stream into the olfactory bulb, where they differentiate into interneurons $(1,3)$; however, after injury, some of these cells migrate toward damaged areas $(4-7)$.

In adult rodent stroke models, acute ischemic brain injury stimulates neurogenesis in the SVZ adjacent to the infarct

Received October 28, 2004; accepted January 26, 2005

Correspondence: Faye S. Silverstein, M.D., University of Michigan, 8301 MSRB 3, Ann Arbor, MI U.S.A. e-mail: fsilvers@med.umich.edu.

This work was supported by USPHS awards NS40824 (F.S.S.) and NS42143 (J.M.P.), and an American Heart Association Grant-in-Aid (J.M.P.).

J.O. and J.M.Pl. contributed equally to this study.

DOI: 10.1203/01.PDR.0000179381.86809.02
(4-7). Some of the neural precursors migrate toward the striatal infarct core and differentiate into both neurons and glia (4-7). In contrast with these findings in adult brain injury models, the first study that evaluated the impact of hypoxicischemic (HI) brain injury on SVZ neurogenesis in the neonatal rodent brain reported that $\mathrm{HI}$ injury [elicited by unilateral carotid ligation and timed exposure to $8 \%$ oxygen in 7-d-old (postnatal day 7 [P7]) rats] acutely depleted neural precursors in the SVZ (8). In contrast, although severe HI insults can injure directly the SVZ (9), we recently found that moderate HI injury in P10 mice resulted in a marked increase in cell proliferation and stimulation of neurogenesis in the ipsilateral SVZ 1-3 wk later (10).

A recent report identified species differences in the pathophysiology of HI injury between neonatal mice and rats, in the context of neuroprotection mechanisms (11), and highlighted the importance of systematic comparisons of outcome in both species to better understand mechanisms of neonatal brain injury and repair. We speculated that, in the neonatal rat, 
injury-induced neurogenesis might be discerned more readily after HI insults that did not cause direct SVZ damage. We therefore used a lesioning protocol that does not typically elicit overt damage in the ipsilateral SVZ in P7 rats to examine whether HI injury can stimulate SVZ neurogenesis in immature rats. To assess SVZ cell proliferation, we evaluated changes in the shape and size of the SVZ 1-3 wk later and estimated numbers of SVZ cells that were labeled with the proliferation marker bromodeoxyuridine (BrdU) at $2 \mathrm{wk}$ after lesioning. To assess neurogenesis, we first performed immunohistochemistry assays to evaluate $\mathrm{HI}$ injury-induced changes in the distribution of doublecortin, a microtubule protein expressed by immature neurons, and then performed double immunofluorescence labeling assays to identify newly generated mature neurons after a 4-wk recovery period.

\section{METHODS}

Animal methods. Protocols were approved by the University of Michigan Committee on Use and Care of Animals. P7 Sprague-Dawley rats (Charles River Laboratories, Wilmington, MA) of both genders were anesthetized (isoflurane inhalation, induction: $3 \%, 3.5 \mathrm{~min}$; maintenance, 1.5\%, <5 min), and the right common carotid artery was ligated, as previously described (12). Pups recovered in a $37^{\circ} \mathrm{C}$ incubator (Hovabator; GQF Manufacturing Co., Savannah, GA; $15 \mathrm{~min}$ ) and were returned to the dams (70 $\mathrm{min})$. Next, they were placed in acrylic containers, partially submerged in a water bath $\left(37^{\circ} \mathrm{C}\right.$, $20 \mathrm{~min}$ ), and then exposed to $8 \% \mathrm{O}_{2} /$ balanced nitrogen for $90 \mathrm{~min}$. Controls included littermates that were exposed to $8 \% \mathrm{O}_{2}$, and untreated animals. Histopathology and regional morphometry (bilateral cerebral hemisphere and SVZ areas) were evaluated 1,2 , or $3 \mathrm{wk}$ after lesioning ( $n=11-12$ /group) and in hypoxia alone $(n=5-6)$ or untreated age-matched controls $(n=5-6)$. Doublecortin immunostaining was evaluated concurrently in lesioned $(n=$ 5-6), hypoxia alone $(n=3)$, and naïve controls $(n=3)$.

In selected experiments, the thymidine analog BrdU (Roche, Mannheim, Germany) was used to label proliferating cells in the $\mathrm{S}$ phase of the cell cycle (13). A BrdU administration protocol that resulted in robust cell labeling in neonatal mice was replicated (10); animals received three daily i.p. injections (100 mg/kg BrdU in sterile PBS) from P12 to 14 (5-7 d after HI injury). SVZ and striatal BrdU immunostaining were quantified at P21 (HI: $n=6$; hypoxia: $n=3$; control: $n=3$ ). In six additional animals, the phenotypes of BrdUlabeled cells at $4 \mathrm{wk}$ after $\mathrm{HI}$ were evaluated using double-label immunofluorescence and confocal microscopy.

Histology. Animals were perfused (0.1 M PBS, $10 \mathrm{~mL} / 10 \mathrm{~g} ; 4 \%$ paraformaldehyde, $20 \mathrm{~mL} / 10 \mathrm{~g}$ ), and brains were removed and cryoprotected. For routine histology, $15-\mu \mathrm{m}$ coronal frozen sections were thaw-mounted onto slides (stored at $-80^{\circ} \mathrm{C}$ ). For $\mathrm{BrdU}$ and doublecortin immunostaining (see below), $60-\mu \mathrm{m}$ free-floating sections were prepared (stored at $-20^{\circ} \mathrm{C}$ ). Freefloating sections $(40$ or $60 \mu \mathrm{m})$ were collected [in $0.1 \mathrm{M}$ Tris ( $\mathrm{pH}$ 7.6)] from P21 and P35 rats for immunofluorescent staining.

For assessing tissue damage and SVZ morphology, equidistant coronal sections in series throughout the striatum were stained with cresyl violet. The high density of cells in SVZ, compared with the adjacent striatum and overlying white matter (see Fig. 1), allows delineation of this structure. A computerized video camera-based image analysis system (with NIH Image v.1.61 software) was used to measure bilateral regional cross-sectional areas of the cerebral hemispheres and dorsolateral SVZ tail in at least six sections per brain. We focused on measurements of this region of the SVZ both because preliminary experiments suggested that $\mathrm{HI}$ injury markedly altered its size and shape and because this region could be identified and outlined consistently (see Fig. 2) in cresyl violet-stained sections.

Immunohistochemistry. BrdU immunostaining was done on six equidistant sections per animal, using a published protocol $(6,10)$. Sections were postfixed in $4 \%$ paraformaldehyde $(10 \mathrm{~min})$, rinsed $(0.1 \mathrm{M}$ Tris, $10 \mathrm{~min})$, denatured (2 $\left.\mathrm{N} \mathrm{HCl}, 37^{\circ} \mathrm{C}, 30 \mathrm{~min}\right)$, rinsed [0.1 M sodium borate $(\mathrm{pH} 8.5), 10 \mathrm{~min}$ ], blocked (10\% horse serum), incubated with a mouse monoclonal anti-BrdU antibody (Roche; $1: 1000$ in $0.1 \mathrm{M}$ Tris/0.1\% Triton X-100/0.05\% bovine albumin, $18 \mathrm{~h}$, $4^{\circ} \mathrm{C}$ ), rinsed, and incubated with biotinylated horse anti-mouse IgG (Vector Labs, Burlingame, CA; $\left.1: 200,25^{\circ} \mathrm{C}, 45 \mathrm{~min}\right)$. Signal was developed using the avidin-biotin method (Vectastain ABC Elite kit; Vector Labs)

Doublecortin immunostaining was used to identify immature neurons (6-8 sections/brain) as previously described $(6,10)$. Briefly, sections were washed [0.1 M Tris ( $\mathrm{pH} 7.6$ ), $15 \mathrm{~min}$ ], incubated with $1 \% \mathrm{H}_{2} \mathrm{O}_{2}$ in $0.1 \mathrm{M}$ Tris (30 min), rinsed [0.1 M Tris buffer/0.1\% Triton X-100 ("Tris-A"), $15 \mathrm{~min} ; 0.1 \mathrm{M}$ Tris/0.1\% Triton X-100/0.05\% BSA ("Tris-B"), 15 min], blocked (15\% normal goat serum in Tris-B, $1 \mathrm{~h}$ ), washed (Tris-A, $15 \mathrm{~min}$; Tris-B, $15 \mathrm{~min}$ ), and incubated with anti-doublecortin antibody [rabbit polyclonal, 1:10,000 in Tris-B, $\left.4^{\circ} \mathrm{C}, 48 \mathrm{~h}(6,10)\right]$. Sections were rinsed and incubated with biotinylated goat anti-rabbit IgG (Vector Labs; 1:200 in Tris-B, $25^{\circ} \mathrm{C}, 45 \mathrm{~min}$ ), and signal was developed using the avidin-biotin method, as above. Selected sections were photographed using a Nikon microphot-SA microscope (Tokyo, Japan) and SPOT Camera (Diagnostic Instruments Inc., Sterling Heights, MI) and imported into Adobe Photoshop v. 5.5 for image processing.

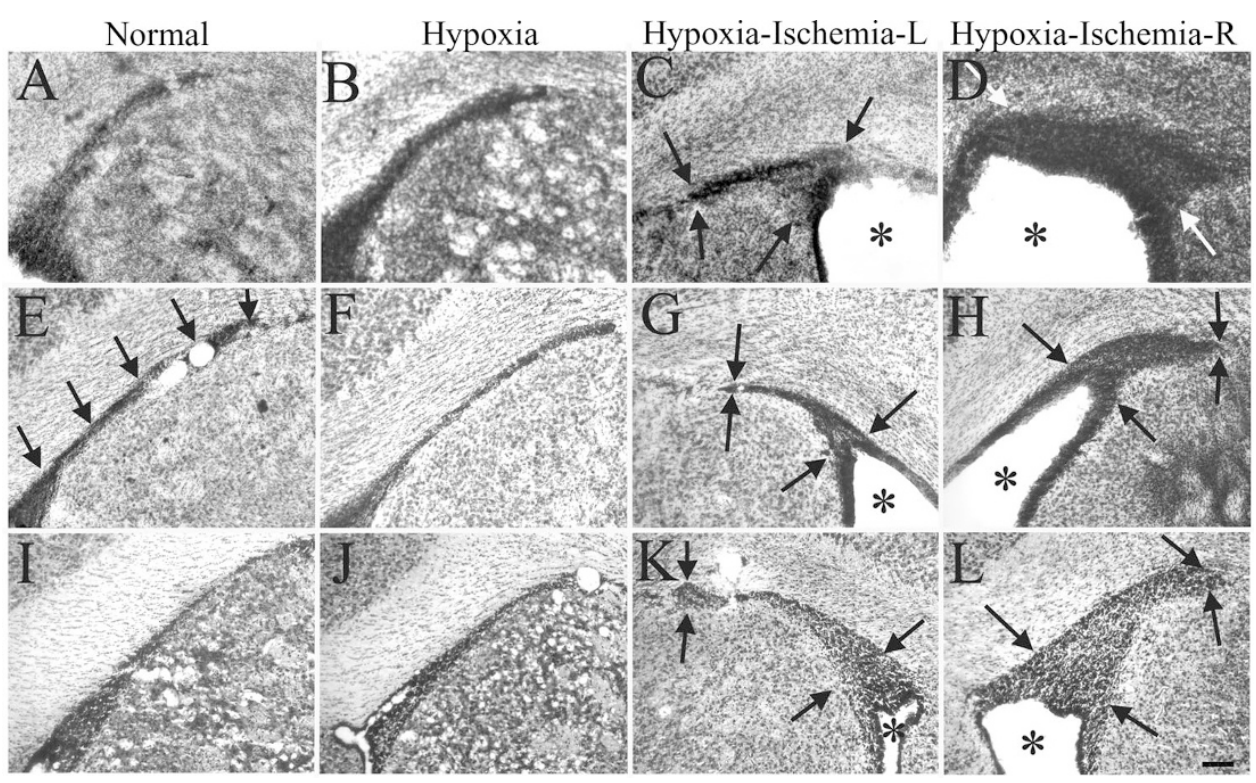

Figure 1. HI-induced changes in SVZ. Cresyl violet-stained coronal brain sections at the level of striatum demonstrate densely packed cells (black arrows in $E$ ) in the dorsolateral tail of the SVZ in normal P14, P21, and P28 animals $(A, E$, and $I)$; in three age-matched animals that were exposed to 90 min of $8 \%$ O on P7 (Hypoxia; $B, F$, and $J)$; and on the left $(C, G$, and $K)$ and right $(D, H$, and $L)$ sides of animals of corresponding ages that underwent HI lesioning on P7 (see "Methods"). There are marked HI injury-induced changes in the shape of the right SVZ at P14 (D, white arrows) that are sustained at P21-28. *Lateral ventricle; in lesioned animals, enlargement of the right lateral ventricle reflects adjacent striatal atrophy. Bar $=0.2 \mathrm{~mm}$. 
A
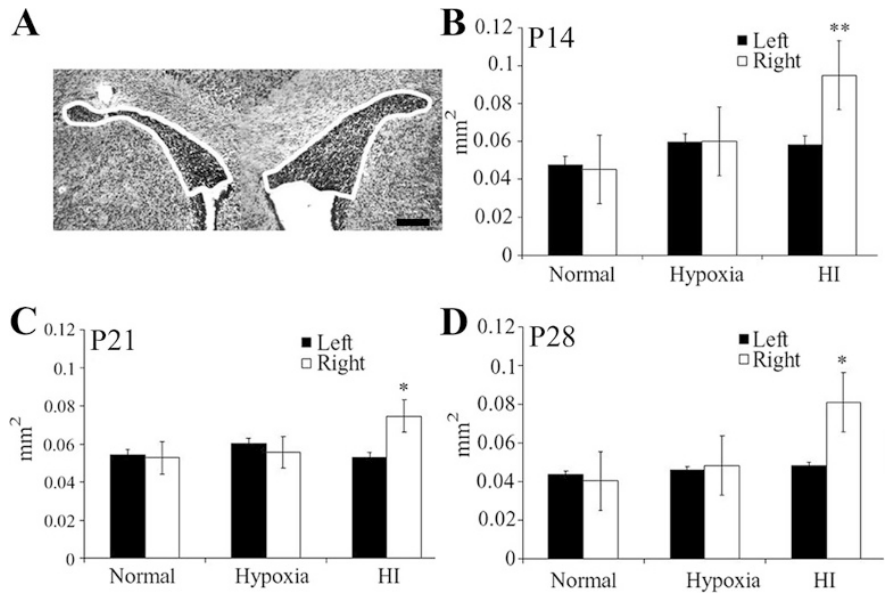

Figure 2. Comparison of bilateral SVZ areas in $\mathrm{HI}$ and control animals. The SVZ dorsolateral tail was outlined, as illustrated in $A$, and measured bilaterally in normal P14, P21, and P28 animals ( $n=5-6 /$ age); in age-matched animals that were exposed to $90 \mathrm{~min}$ of $8 \% \mathrm{O}_{2}$ on P7 (Hypoxia; $n=5-6$ ); and in animals that underwent right carotid ligation and $90 \mathrm{~min}$ of $8 \% \mathrm{O}_{2}$ exposure on P7 $(n=11-12)$. Bilateral SVZ areas were compared at P14 (B), P21 $(C)$, and P28 $(D)$. At all three ages, bilateral SVZ areas were similar in the normal and hypoxia groups, and the left (contralateral) SVZ of lesioned animals was not enlarged. The right SVZ areas of $\mathrm{HI}$ animals were significantly increased compared with the contralateral SVZ and both control groups. Values are expressed as mean $\left(\mathrm{mm}^{2}\right) \pm \mathrm{SD}$; at each age; values were compared with ANOVA, $* * p<0.01, * p<0.05$. Bar $=0.1 \mathrm{~mm}$.

Immunofluorescent assays. Cell phenotype was determined using doublelabel immunofluorescent staining. Antibodies to detect immature neurons (doublecortin, rabbit polyclonal), mature neurons [neuronal nuclear protein (NeuN), mouse monoclonal; Chemicon, Temecula, CA], astrocytes [glial fibrillary acidic protein (GFAP), mouse monoclonal; Sigma Chemical Co., St. Louis, MO], or oligodendrocytes (RIP, mouse monoclonal; Developmental Hybridoma Bank, University of Iowa, Iowa City, IA) were combined with a rat monoclonal anti-BrdU antibody (Immunologicals Direct, Oxfordshire, UK). Staining methods followed published protocols $(6,10)$. Sections were washed [0.1 M Tris ( $\mathrm{pH} 7.6)]$, incubated in blocking buffer $(1 \mathrm{~h})$, and incubated with the primary $\left(1^{0}\right)$ antibody (overnight, $4^{\circ} \mathrm{C}$; doublecortin, 1:1000; NeuN, 1:1000; GFAP, 1:500; RIP, 1:200). Sections were washed (TBS), fixed (4\% paraformaldehyde, $20 \mathrm{~min})$, denatured $\left(2 \mathrm{~N} \mathrm{HCl}, 37^{\circ} \mathrm{C}, 30 \mathrm{~min}\right)$, neutralized [0.1 M sodium borate ( $\mathrm{pH} 8.5)]$, blocked, rinsed, and incubated with anti-BrdU antibody $(1: 200)$ together with the initial $1^{\circ}$ antibody $\left(4^{\circ} \mathrm{C}\right.$, overnight). Sections were washed, blocked, incubated with secondary antibodies [Alexa 594 -conjugated goat anti-rat IgG and Alexa 488 goat anti-mouse IgG (Molecular Probes, Eugene, OR); $\left.1: 800,25^{\circ} \mathrm{C}, 1 \mathrm{~h}\right]$. Sections were mounted and coverslipped using an anti-fade medium (Molecular Probes). Immunofluorescent-stained sections were analyzed using a Zeiss LSM 510 laser confocal microscope (Oberkochen, Germany). Single images and z-series stacks ( $1 \mu \mathrm{m}$ optical slice thickness) were imported into Adobe Photoshop v. 7.0 for processing and analysis.

Quantification of BrdU immunostaining. Unbiased stereologic analysis was applied to count BrdU-labeled cells in the left and right SVZ and striatum of P21 normal $(n=3)$, hypoxia $(n=3)$, and $\mathrm{HI}(n=6)$ rats; in two HI rats, inadequate tissue preservation precluded accurate striatal counts. Systematic random sampling was obtained using every fourth section in a series of six equidistant coronal sections through the striatal SVZ. Parameters were set for BrdU-positive cell counting by random selection of a section from each animal; this section was used to determine cell counting frame size, number of samples per section, and spacing of sample sites; designated areas were outlined at $\times 4$ magnification. Counts were performed using a $\times 100$ objective lens on a Leica DMR light microscope with LEP motorized stage, Optronics camera, and the StereoInvestigator v.5.0 computer program (MicroBrightField, Colchester, VT). Total cell numbers were estimated using the Optical Fractionator technique (14).

Statistical analysis. A microcomputer-based statistics program (GraphPad Prism, v.5.0, Cary, NC) was used for data analysis. SVZ volumes and cel counts were compared by ANOVA; Dunnett's post hoc $t$ tests were applied to evaluate differences from control values. Comparisons were interpreted as significant when associated with $p \leq 0.05$.

\section{RESULTS}

Figure 1 demonstrates cresyl violet-stained coronal sections at the level of midstriatum of normal, hypoxia alone, and HI animals at P14, P21, and P28. The SVZ constitutes a narrow band of densely packed cells that expands into an infracallosal, dorsolateral tail. The severity of injury was similar in all three groups of HI animals, based on measurement of cerebral hemisphere areas; mean reductions in ipsilateral cerebral hemisphere size were $17 \%$ at $\mathrm{P} 14,28 \%$ at $\mathrm{P} 21$, and $25 \%$ at $\mathrm{P} 28$. The SVZ size and shape were the same at each age in the normal and hypoxia-alone groups. HI injury-induced changes in the size and shape of the ipsilateral SVZ were evident 1-3 wk after lesioning. Although there were no consistent changes in the contralateral SVZ, in some animals, the left SVZ appeared subtly thickened in comparison with controls (Fig. $1 K$ ). In contrast, HI injury caused marked expansion of the right SVZ at all three ages (Fig. $1 D, H$, and $L$ ). The enlargement of the adjacent lateral ventricle (indicated with asterisks) reflects striatal atrophy and is a typical feature of this lesion.

For estimating the magnitude of SVZ expansion, the dorsolateral tail was outlined (as illustrated in Fig. 2A) bilaterally in normal P14, P21, and P28 animals; in age-matched animals that were exposed to $90 \mathrm{~min}$ of $8 \% \mathrm{O}_{2}$ on P7; and in corresponding $\mathrm{HI}$ animals. At all three ages, bilateral SVZ areas were equal in the normal and hypoxia groups, and at each age, areas were the same in the normals, hypoxia group, and the left SVZ of lesioned animals. At all three ages, the right SVZ areas of $\mathrm{HI}$ animals were increased (mean increase 40-66\%) compared with the contralateral SVZ or both control groups (Fig. 2, ANOVA, post hoc $t$ tests: at $\mathrm{P} 14, p<0.01$; at $\mathrm{P} 21$ and $\mathrm{P} 28, p<0.05$ ).

BrdU labeling studies were performed to assess $\mathrm{HI}$-induced SVZ cell proliferation. BrdU-labeled cells were detected by immunohistochemistry in all animals evaluated. Figure 3 shows typical distributions of $\mathrm{BrdU}$ at P21, 1 we after the final BrdU injection. BrdU immunostaining was always concentrated in the SVZ and was also evident in more scattered cells of the adjacent overlying corpus callosum and in the striatum (Fig. $3 A$ and $B$ ). Figure $3 C$ and $D$ illustrates the similar distribution of BrdU-labeled cells in an animal that was exposed to $8 \% \mathrm{O}_{2}$ (90 min on P7). In a lesioned animal (Fig. $3 E-H)$, BrdU-labeled cells are concentrated in the right SVZ (Fig. $3 F$ and $G$ ) and are also clustered in the adjacent lesioned striatum (Fig. $3 F$, *; higher magnification in $H$ ).

Unbiased stereologic analysis was used to estimate numbers of BrdU-labeled cells in SVZ and striatum in P21 animals from the three groups (Fig. 4). Figure $4 A$ illustrates the areas that were outlined for SVZ and striatal cell counting. In the normal and hypoxia control groups, measurements were equivalent bilaterally, and values from the left and right sides therefore were pooled for analysis; in the HI animals, values from the left and right sides were analyzed independently. In P21 normals and hypoxia-exposed animals, BrdU-labeled cell numbers in the SVZ and striatum were similar; cell counts in the left SVZ and striatum of lesioned animals did not differ from either control group (Fig. $4 B$ and $C$ ). In the right SVZ, mean BrdUpositive cell counts were $80 \%$ higher than in the normals (mean counts 66,080 versus 36,680; ANOVA, $p<0.02$; post hoc $t$ 


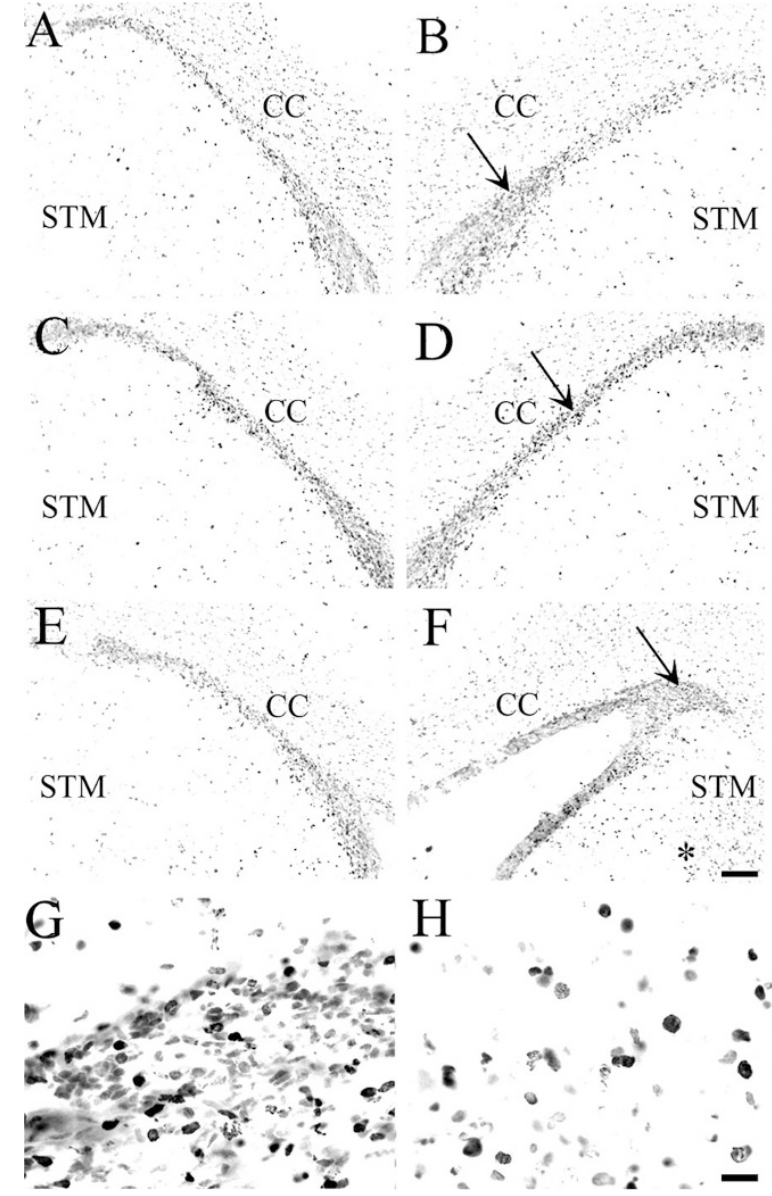

Figure 3. BrdU-labeled cells in SVZ. Results of BrdU immunohistochemistry assays demonstrate the distribution of BrdU-labeled cells bilaterally in three P21 animals that received BrdU injections on P12-14 (see "Methods"). ( $A$ and $B$ ) High concentration of BrdU-labeled cells in the normal SVZ (black arrows), as well as staining in the adjacent striatum (STM) and overlying corpus callosum (CC). The distribution of BrdU-labeled cells is similar in an animal that was exposed to $8 \% \mathrm{O}_{2}(90 \mathrm{~min})$ on $\mathrm{P} 7(C$ and $D)$. In an animal that underwent right carotid ligation and $90 \mathrm{~min}$ of $8 \% \mathrm{O}_{2}$ exposure on $\mathrm{P} 7$, BrdU-labeled cells are concentrated in the right SVZ ( $F$ and higher magnification in $G)$ and are also clustered in the adjacent lesioned striatum $(F, *$; higher magnification in $H$ ). Bars $=0.1 \mathrm{~mm}$ in $A-F ; 16.7$ in $\mu \mathrm{m} G$ and $H$.

test, $p<0.01$ ). In the lesioned right striatum, BrdU labeling increased similarly (ANOVA, $p=0.006$; post hoc $t$ test comparing values in HI right striatum and normal, $p<0.01$ ).

Doublecortin is a microtubule-associated protein expressed by immature neurons. Doublecortin immunostaining was examined to evaluate whether HI injury increased SVZ and striatal neurogenesis (Fig. 5). Figure 5 demonstrates a distinct band of doublecortin immunostaining concentrated in the SVZ of normal P14 (Fig. 5A), P21 (Fig. 5E), and P28 (Fig. 5I) animals; the pattern is similar in corresponding age-matched animals that were exposed to $8 \% \mathrm{O}_{2}$ for $90 \mathrm{~min}$ on $\mathrm{P} 7$ (Fig. $5 B$, $F$, and $J$ ) and on the left side of $\mathrm{HI}$ animals (Fig. $5 C, G$, and $K$ ). In the HI group, doublecortin immunostaining is substantially increased in the right SVZ at P14 (Fig. 5D), P21 (Fig. 5H), and P28 (Fig. $5 L$ ) and is concentrated in the dorsolateral tail.

Immunofluorescence assays confirmed this finding (Fig. 6AC). In a P21 HI sample on the left side (Fig. 6A), there is a narrow band of doublecortin (red) immunostaining in the SVZ,
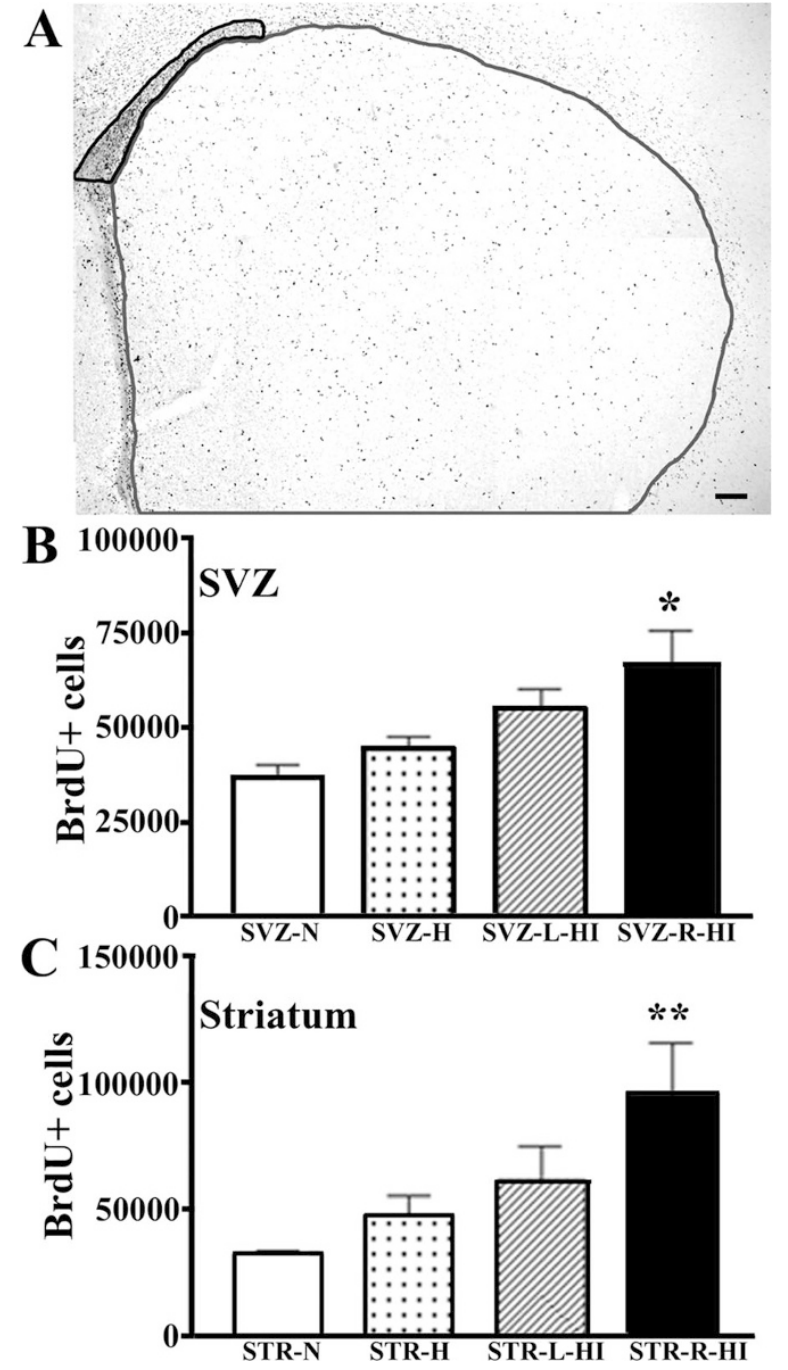

Figure 4. Quantification of BrdU immunostaining. Unbiased stereologic analysis was used to estimate numbers of BrdU-labeled cells in SVZ and striatum of three groups of P21 animals that had received BrdU injections on P12-14, normals $(n=3)$, animals that were exposed to $8 \% \mathrm{O}_{2}$ for $90 \mathrm{~min}(\mathrm{H}$; $n=3$ ), and animals that underwent right carotid ligation and $90 \mathrm{~min}$ of $8 \% \mathrm{O}_{2}$ exposure on P7 (HI; $n=6$ ). (A) Areas that were outlined for SVZ and striatal cell counting (see "Methods"). In both SVZ $(B)$ and striatum $(C)$, BrdU-labeled cell numbers increased ipsilateral to the infarct compared with normals (ANOVA, $* p<0.02 ; * * p<0.01$ ). Bar $=0.2 \mathrm{~mm}$.

and GFAP (green) immunostaining is concentrated in the overlying corpus callosum; in the HI lesion territory (Fig. $6 B$ and $C$ ), there is a marked increased in doublecortin immunostaining extending from the enlarged SVZ and a marked increase in GFAP both in the lesioned striatum and in the corpus callosum. Figure $6 C$ illustrates that discrete chains of doublecortin immunostained cells (arrowheads) extend from the SVZ into the lesioned striatum. Double-label immunofluorescence and confocal microscopy were used to determine the fate of cells that incorporated BrdU. Animals underwent $\mathrm{HI}$ at $\mathrm{P} 7$, received BrdU on P12-14, and were evaluated at P21 (data not shown) or P35 (Fig. 6). Figure $6 D-O$ illustrate typical findings at $\mathrm{P} 35$. BrdU immunostaining was most pronounced in the dorsolateral striatum, adjacent to the infarct core; BrdUpositive cells were also identified adjacent to the ipsilateral 


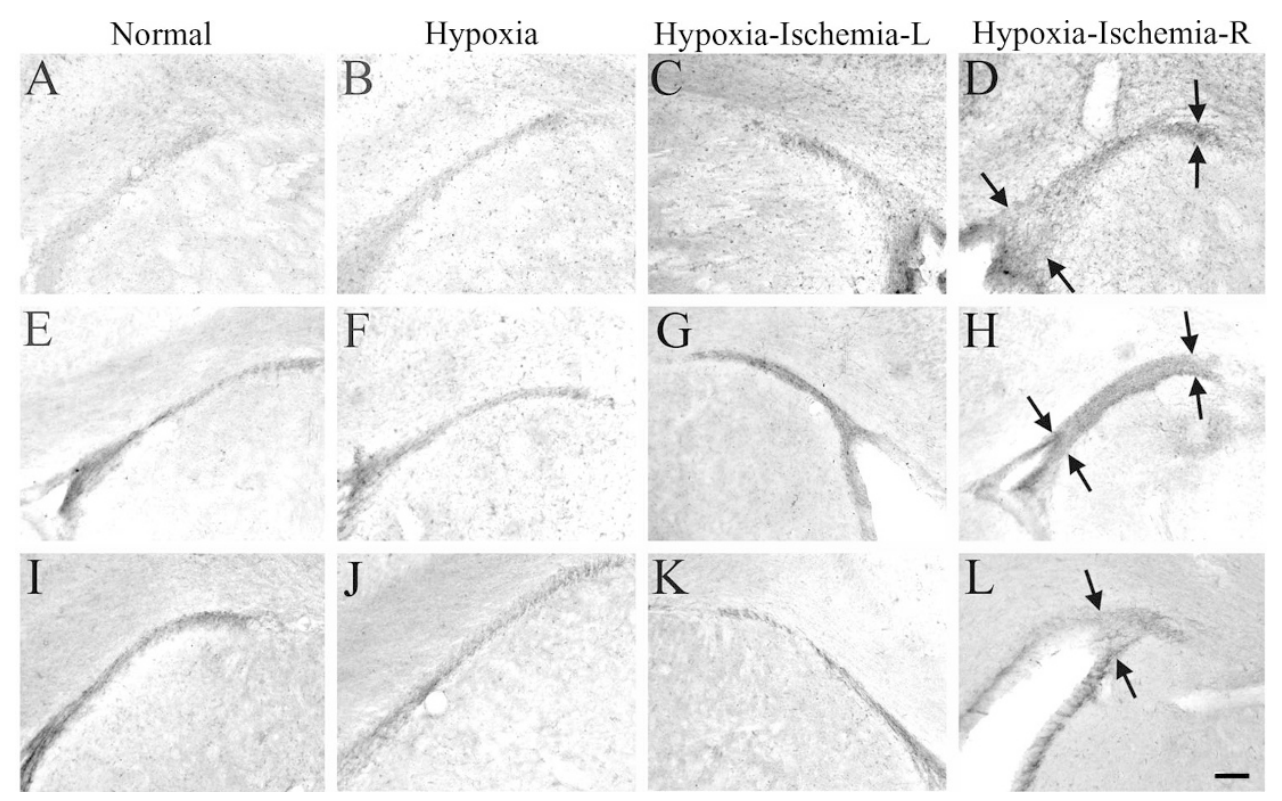

Figure 5. Doublecortin immunostaining in SVZ. Doublecortin immunostaining is concentrated in the SVZ of normal P14 $(A)$, $\mathrm{P} 21(E)$, and $\mathrm{P} 28(I)$ animals, and the pattern is similar in animals of the same ages that were exposed to $8 \% \mathrm{O}_{2}$ for $90 \mathrm{~min}$ on $\mathrm{P} 7$ (Hypoxia; $B, F$, and $J$ ). In animals that underwent right carotid ligation and $90 \mathrm{~min}$ of $8 \% \mathrm{O}_{2}$ exposure on P7 (Hypoxia-Ischemia), doublecortin immunostaining in the left SVZ $(C, G$, and $K)$ is similar to that of normals. In the right $(\mathrm{R}) \mathrm{SVZ}$, at P14 (D), P21 $(H)$, and P28 $(L)$, immunostaining is increased and is concentrated in the dorsolateral tail of the SVZ (black arrows). Bar $=$ $0.1 \mathrm{~mm}$.

ventricle, in the SVZ, and in the corpus callosum/external capsule.

Most mature neurons throughout the embryonic and adult mammalian nervous system express NeuN protein; it is first detectable at developmental time points that correspond with the withdrawal of the neuron from the cell cycle and/or with the initiation of terminal differentiation (15). NeuN immunostaining was markedly reduced in the striatal lesion core, but many NeuN-positive cells were identified in the perilesional striatum (Fig. 6D). With rigorous confocal analysis (including z-series) of multiple sections from three $\mathrm{HI}$ animals, no BrdU/ NeuN double-labeled cells were identified, although many BrdU-positive cells were in close proximity with NeuNexpressing neurons ["satellite" cells, as described in (16), in Fig. $6 E$ and $F$ ). To verify that technical factors did not account for lack of BrdU/NeuN double labeling, we also evaluated a hippocampal section; Fig. $6 I$ illustrates a BrdU/NeuN doublelabeled neuron (arrow) within the densely packed NeuNpositive neurons of the dentate gyrus. In contrast with the paucity of BrdU/NeuN double-labeled cells in the lesioned striatum and adjacent corpus callosum, many BrdU/GFAP double-labeled astrocytes (Fig. $6 J-L$ ) and BrdU-RIP doublelabeled oligodendroglia were identified (Fig. 6M-O).

\section{DISCUSSION}

Our results demonstrate that in neonatal rats, HI injury stimulates SVZ cell proliferation and neurogenesis. One to 3 wk after lesioning, regional morphometric measurements of the SVZ dorsolateral tail demonstrated a substantial change in the shape and size of the SVZ ipsilateral to the infarct. Quantitative analysis of BrdU labeling in tissue samples obtained 2 wk after injury (and $1 \mathrm{wk}$ after BrdU administration) indicated that BrdU-labeled cell numbers in the SVZ and striatum ipsilateral to the infarct almost doubled compared with agematched normals or animals that were exposed to the same duration of hypoxia alone. Increased doublecortin immunostaining in these regions provided evidence of HI injuryinduced neurogenesis. However, in the injured striatum, the majority of BrdU-labeled cells that persisted for at least 2-3 wk after the final BrdU injection displayed a glial phenotype, and it seemed that few, if any, newly generated mature neurons survived.

We selected a BrdU administration protocol (5-7 d after lesioning) that we anticipated would be optimal for labeling of newly generated neurons, on the basis of results of adult rodent stroke studies (6), and that would minimize the possibility of BrdU incorporation associated with DNA repair (17). Evidence of increased doublecortin immunostaining in the ipsilateral SVZ at 1-2 wk after lesioning, which coincided with the period subsequent to BrdU administration, provided support for this approach.

Doublecortin is a microtubule-associated protein that is expressed in migratory neuroblasts (18). Doublecortin immunoreactivity identified immature neurons 1-3 wk after HI. Increased doublecortin immunostaining was initially restricted to the ipsilateral SVZ. Subsequently, doublecortin-expressing cells were identified both in the enlarged SVZ and in the injured striatum. A distinctive feature of striatal doublecortin-positive cells was their frequent arrangement in chains, apposed to GFAP + astrocyte processes; this pattern suggested that glia were guiding the migration of these cells and was reminiscent of neuroblast migration to the olfactory bulb via the rostral migratory stream (19). At $3 \mathrm{wk}$ after injury, doublecortin immunoreactivity remained increased, to a lesser degree, in the ipsilateral SVZ and striatum. 


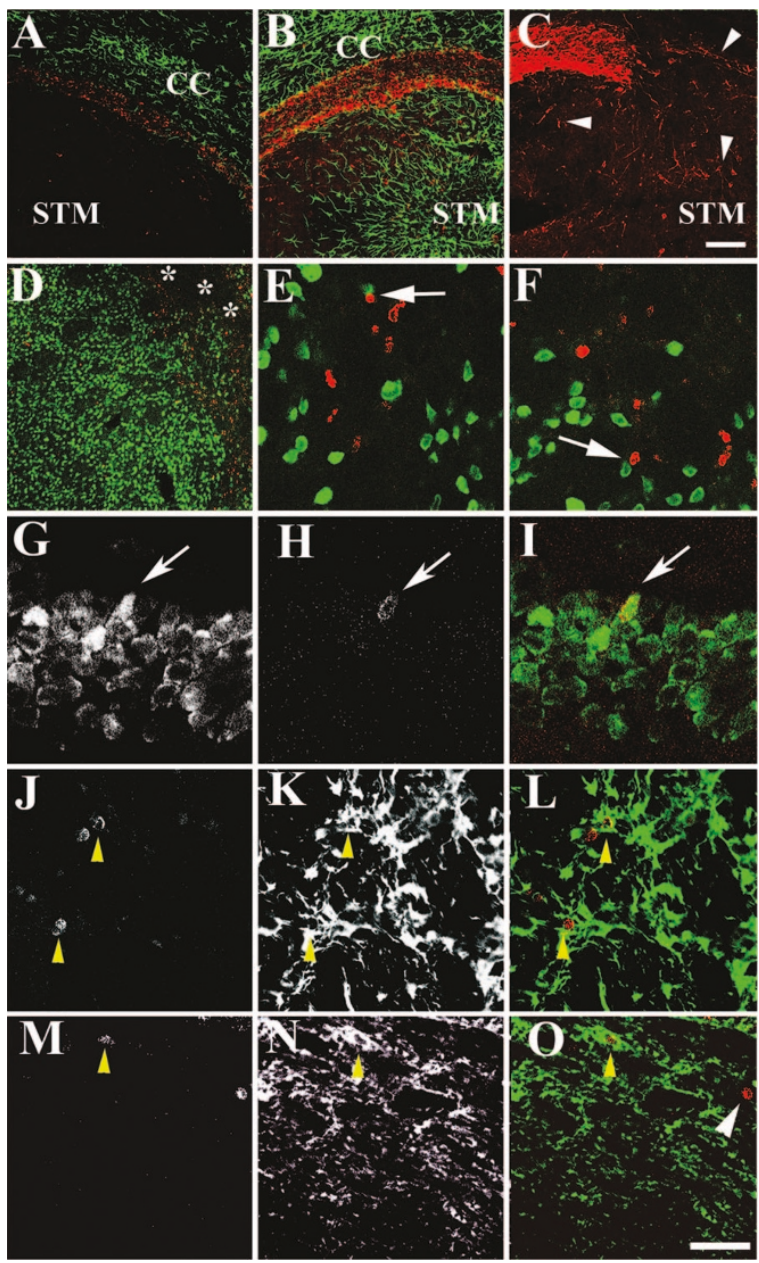

Figure 6. Double-label immunofluorescence assays to evaluate HI injuryinduced neurogenesis and gliogenesis. At 2 wk after $\mathrm{HI}(A-C)$ a narrow band of doublecortin-positive cells (red) is seen in the left SVZ, and GFAP (green) immunostaining is concentrated in the overlying corpus callosum; in the $\mathrm{HI}$ lesion territory ( $B$ and $C$ ), doublecortin immunoreactivity is markedly increased in the dorsolateral SVZ and striatum (STM), and GFAP expression is increased both in the lesioned STM and in the corpus callosum $(\mathrm{CC}$, in $B)$. $(C)$ Doublecortin-immunoreactive cells (arrowheads) extend in discrete chains or clusters from the SVZ into the lesioned striatum. At 4 wk after HI injury, striatal NeuN immunostaining (green in $D-F$ ) is relatively preserved medially and markedly reduced laterally in the infarct core (*). Animals received BrdU 5-7 d after lesioning (see "Methods"). Confocal analysis of striatal NeuN (green) and BrdU (red) immunostaining $(E$ and $F$ ) identified many immunoreactive cells but no co-localization; typical BrdU-positive satellite cells appear in close proximity to NeuN immunoreactive neurons (arrows in $E$ and $F)$. To confirm that we were able to detect co-localization of BrdU and NeuN, we evaluated a tissue sample from hippocampal dentate gyrus $(G-I)$; among densely packed NeuN-positive neurons ( $G$, green in $I)$, note a newly generated mature neuron (arrow). $(J-L)$ BrdU-GFAP immunoreactive astrocytes in the right striatum [co-localization (arrowheads) of GFAP immunostaining ( $K$, green in $L$ ) and BrdU immunostaining $(J$, red in $L)]$. $(M-O)$ HI lesioning does result in generation of new oligodendroglia [co-localization (yellow) of RIP immunostaining $(N$, green in $O)$ and $\operatorname{BrdU}$ immunostaining $(M$, red in $O)$ in right in corpus callosum]. Bars $=50 \mu \mathrm{m}$ in $C ; 15.9 \mu \mathrm{m}$ in $O$.

In contrast with findings in adult rat stroke models $(6,7)$, we could not identify newly formed mature striatal neurons at 4 wk after HI injury. It is unlikely that technical limitations account for this result, because we were able to detect BrdU/ NeuN double-labeled cells in the hippocampus. Absence of double-labeled striatal neurons could result from dilution of nuclear BrdU after multiple divisions of BrdU-labeled progenitors, and it is possible that different BrdU administration protocols would have resulted in labeling of newly formed mature neurons, yet, particularly in view of similar findings in neonatal mice (10), the most likely explanation for this finding is that the injured striatum, at this developmental stage, does not provide an environment that is conducive to the maturation or survival of newly formed neurons. Another mechanism is suggested by a recent study of acute SVZ cell death in the same neonatal HI model; Romanko et al. (20) found that neuronal progenitors were more vulnerable to $\mathrm{HI}$ than SVZ stem cells. It is possible that the depletion of this pool of cells is a contributing factor, despite the apparently robust production of immature neurons, based on doublecortin immunostaining.

We focused on analysis of striatal neurogenesis for several reasons, including proximity of this region to the SVZ, the vulnerability of the neonatal striatum to HI injury, and the recent reports of ischemia-induced striatal neurogenesis in adult stroke models. Levison et al. (8) reported that in P7 rats, severe HI injury depleted SVZ progenitor cells, and this prompted us to incorporate a lesioning protocol that elicited relatively mild HI injury. Under these lesioning conditions, there was only modest and variable injury in the ipsilateral cortex and hippocampus, and it was not feasible to systematically evaluate neurogenesis in these regions. We did note increased proliferation and gliogenesis in the ipsilateral corpus callosum. In a recent study of HI injury-induced generation of oligodendroglia in this model, we found that in both ipsilateral and contralateral corpus callosum, the number of newly generated oligodendroglia was four times higher than in controls at 1 mo after lesioning (12).

Of interest, neurogenesis has been documented in other regions of the developing rat brain. In slightly older (P10) animals, using a similar approach to identify newly generated mature neurons (BrdU/NeuN double labeling), Kolb et al. (21) found that aspiration injury in the medial frontal cortex but not in other cortical regions stimulated neurogenesis. Daval et al. (22) recently reported that in P1 rats, a brief (20 $\mathrm{min}$ ) period of anoxia induced apoptosis, followed by neurogenesis, and apparent anatomic recovery in the CA1 subfield of the hippocampus; they also observed increased SVZ proliferation and increased expression of markers for mature neurons in the SVZ $20 \mathrm{~d}$ later but did not demonstrate double labeling of any of these cells. In contrast, in a similar neonatal asphyxia model, Scheppens et al. (23) reported up-regulation of hippocampal proliferation but no changes in SVZ proliferation $5 \mathrm{~d}$ later. Together, our results and these cited studies illustrate that maturational stage, nature of the $\mathrm{HI}$ insult, anatomic site of injury, and timing of the BrdU labeling regimen all are important variables in studies of neonatal neurogenesis.

The molecular signals that trigger SVZ proliferation and differentiation of these newly generated cells after HI injury are uncertain. Specific growth factors, such as fibroblast growth factor 2, have been implicated as regulators of SVZ proliferation in adult (16) and neonatal brain (24). Of note, we found many "satellite" cells, BrdU-positive cells closely apposed to mature, NeuN-positive neurons, in the injured striatum (see 
Fig. $6 E$ and $F$ ). Kuhn et al. (16) found similar results when they infused fibroblast growth factor 2 intraventricularly into adult rat brain; in the adult rat striatum, they found no BrdU/ NeuN double labeling but many BrdU-positive nuclei closely associated with neurons. Thirty percent of these satellite cells expressed GFAP. We speculate that endogenous growth factors that are up-regulated in the injured neonatal brain play a pivotal role in regulating the differentiation and/or maturation of newly generated cells toward a glial fate.

Comparison between the results that we obtained in neonatal rats and those in a previous study in neonatal mice (10) revealed both similarities and differences. In both species, acute HI injury stimulated SVZ proliferation and ipsilateral neurogenesis, and in both, after a 1-mo recovery period, there were many newly generated surviving glia without newly generated mature striatal neurons. In neonatal rats, hypoxia alone $\left(8 \% \mathrm{O}_{2}, 90 \mathrm{~min}\right)$ had no effect on $\mathrm{SVZ}$ proliferation, whereas in mice, a shorter period of hypoxia $\left(10 \% \mathrm{O}_{2}, 45 \mathrm{~min}\right)$ resulted in a 2-fold increase in SVZ BrdU+ cell numbers (but with no evidence of increased neurogenesis). In addition, in the HI neonatal rats, the magnitude of stimulation of SVZ proliferation and striatal BrdU cell counts at corresponding time intervals after lesioning were less pronounced than in neonatal mice (in mice, 4 -fold increase over controls, and in rats, $<2$-fold increase). The severity of HI tissue damage was similar (25-35\% hemisphere atrophy in mice versus $17-28 \%$ damage in the rats), and this factor cannot account for differences of this magnitude. Other inter-rodent species differences in regulation of SVZ proliferation have been reported; Goings et al. (25) found that cortical lesions decreased proliferation in the SVZ in mice, whereas the same lesion stimulated SVZ proliferation in rats. Identification of the factors that account for differential responses between species, as well as between animals of the same species at different maturational stages, will likely reveal important mechanisms that regulate injuryinduced stem cell proliferation and neurogenesis.

Our results provide evidence that the injured neonatal mammalian forebrain has regenerative potential. These findings raise many provocative questions. Currently, it is unknown whether acute brain injury elicits similar responses in human neonates. Moreover, it should be recognized that newly generated neurons would have the potential either to enhance or to disrupt recovery after HI injury. Whether exogenous administration of specific trophic factors can improve survival of newly generated neurons in the injured neonatal brain, whether this would result in improved functional outcome, and, most important, whether these findings can be extended to clinical applications represent critically important questions for future research.

\section{REFERENCES}

1. Lois C, Alvarez-Buylla A 1993 Proliferating subventricular zone cells in the adult mammalian forebrain can differentiate into neurons and glia. Proc Natl Acad Sci USA 90:2074-2077

2. Goldman JE 1995 Lineage, migration, and fate determination of postnatal subventricular zone cells in the mammalian CNS. J Neurooncol 24:61-64

3. Luskin MB 1993 Restricted proliferation and migration of postnatally generated neurons derived from the forebrain subventricular zone. Neuron 11:173-189

4. Zhang RL, Zhang ZG, Zhang L, Chopp M 2001 Proliferation and differentiation of progenitor cells in the cortex and the subventricular zone in the adult rat after focal cerebral ischemia. Neuroscience 105:33-41

5. Jin K, Minami M, Lan JQ, Mao XO, Batteur S, Simon RP, Greenberg DA 2001 Neurogenesis in dentate subgranular zone and rostral subventricular zone after focal cerebral ischemia in the rat. Proc Natl Acad Sci USA 98:4710-4715

6. Parent JM, Vexler ZS, Gong C, Derugin N, Ferriero DM 2002 Rat forebrain neurogenesis and striatal neuron replacement after focal stroke. Ann Neurol 52:802813

7. Arvidsson A, Collin T, Kirik D, Kokaia Z, Lindvall O 2002 Neuronal replacement from endogenous precursors in the adult brain after stroke. Nat Med 8:963-970

8. Levison SW, Rothstein RP, Romanko MJ, Snyder MJ, Meyers RL, Vannucci SJ 2001 Hypoxia/ischemia depletes the rat perinatal subventricular zone of oligodendrocyte progenitors and neural stem cells. Dev Neurosci 23:234-247

9. Skoff RP, Bessert DA, Barks JD, Song D, Cerghet M, Silverstein FS 2001 Hypoxicischemic injury results in acute disruption of myelin gene expression and death of oligodendroglial precursors in neonatal mice. Int J Dev Neurosci 19:197-208

10. Plane JM, Liu R, Wang TW, Silverstein FS, Parent JM 2004 Neonatal hypoxicischemic injury increases forebrain subventricular zone neurogenesis in the mouse. Neurobiol Dis 16:585-595

11. Tsuji M, Wilson MA, Lange MS, Johnston MV 2004 Minocycline worsens hypoxicischemic brain injury in a neonatal mouse model. Exp Neurol 189:58-65

12. Zaidi AU, Bessert DA, Ong JE, Xu H, Barks JD, Silverstein FS, Skoff RP 2004 New oligodendrocytes are generated after neonatal hypoxic-ischemic brain injury in rodents. Glia 46:380-390

13. Miller MW, Nowakowski RS 1988 Use of bromodeoxyuridine-immunohistochemistry to examine the proliferation, migration and time of origin of cells in the central nervous system. Brain Res 457:44-52

14. West MJ, Slomianka L, Gundersen HJ 1991 Unbiased stereological estimation of the total number of neurons in the subdivisions of the rat hippocampus using the optical fractionator. Anat Rec 231:482-497

15. Mullen RJ, Buck CR, Smith AM $1992 \mathrm{NeuN}$, a neuronal specific nuclear protein in vertebrates. Development 116:201-211

16. Kuhn HG, Winkler J, Kempermann G, Thal LJ, Gage FH 1997 Epidermal growth factor and fibroblast growth factor- 2 have different effects on neural progenitors in the adult rat brain. J Neurosci 17:5820-5829

17. Cooper-Kuhn CM, Kuhn HG 2001 Is it all DNA repair? Methodological considerations for detecting neurogenesis in the adult brain. Brain Res Dev Brain Res 134:13-21

18. Gleeson JG, Lin PT, Flanagan LA, Walsh CA 1999 Doublecortin is a microtubuleassociated protein and is expressed widely by migrating neurons. Neuron 23:257-271

19. Lim DA, Alvarez-Buylla A 1999 Interaction between astrocytes and adult subventricular zone precursors stimulates neurogenesis. Proc Natl Acad Sci USA 96:75267531

20. Romanko MJ, Rothstein RP, Levison SW 2004 Neural stem cells in the subventricular zone are resilient to hypoxia/ischemia whereas progenitors are vulnerable. J Cereb Blood Flow Metab 24:814-825

21. Kolb B, Gibb R, Gorny G, Whishaw IQ 1998 Possible regeneration of rat medial frontal cortex following neonatal frontal lesions. Behav Brain Res 91:127-141

22. Daval JL, Pourie G, Grojean S, Lievre V, Strazielle C, Blaise S, Vert P 2004 Neonatal hypoxia triggers transient apoptosis followed by neurogenesis in the rat CA1 hippocampus. Pediatr Res 55:561-567

23. Scheepens A, Wassink G, Piersma MJ, Van de Berg WD, Blanco CE 2003 A delayed increase in hippocampal proliferation following global asphyxia in the neonatal rat. Brain Res Dev Brain Res 142:67-76

24. Ganat Y, Soni S, Chacon M, Schwartz ML, Vaccarino FM 2002 Chronic hypoxia up-regulates fibroblast growth factor ligands in the perinatal brain and induces fibroblast growth factor-responsive radial glial cells in the sub-ependymal zone. Neuroscience 112:977-991

25. Goings GE, Wibisono BL, Szele FG 2002 Cerebral cortex lesions decrease the number of bromodeoxyuridine-positive subventricular zone cells in mice. Neurosci Lett 329:161-164 